\title{
O Ensino da Língua Brasileira de Sinais na EducaÇáo Infantil para Crianças Ouvintes e Surdas: Consideraçóes com Base na Psicologia Histórico-Cultural
} Brazilian Sign Language Instruction for Deaf and Hearing Children in EARly Childhood EDUCation: Considerations Based on CulturalHistoRICAL PSYCHOLOGY

\author{
Hivi de Castro Ruiz MARQUES ${ }^{1}$ \\ Sonia Mari Shima BARROCO ${ }^{2}$ \\ Tânia dos Santos Alvarez da SILVA ${ }^{3}$
}

\begin{abstract}
RESUMO: este artigo objetiva expor consideraçôes teóricas a respeito do ensino da Língua Brasileira de Sinais (Libras) na educação infantil como recurso na mediaçáo entre crianças ouvintes e surdas, considerando a importância do mesmo para a inclusão, e discutir seu impacto sobre o desenvolvimento humano, sob a perspectiva da Psicologia Histórico-Cultural (PHC). O conteúdo resulta de investigação bibliográfico-conceitual desenvolvida no período de 2011-2012. Entendemos que o ensino de Libras pode favorecer a aprendizagem e o desenvolvimento de crianças surdas e ouvintes, permitindo, sobretudo, àquelas multiplicar o número de interlocutores. A Libras oportuniza trocas linguísticas efetivas entre os pares surdos e ouvintes, e às crianças ouvintes oferta o acesso a um universo cultural desconhecido. Estudos de fontes primárias (publicaçôes soviéticas) e secundárias (publicaçôes mais recentes sobre a defectologia vygotskiana, o ensino da Libras e a linguagem) apontam a possibilidade de desenvolvimento de crianças ouvintes e surdas no que concerne à linguagem, sendo importante o ensino da Libras como segunda língua, enquanto recurso para crianças ouvintes. Podemos concluir quanto é necessário incrementar o ensino da Libras, e para isso a legislação regulamentada deve ser de fato cumprida. A Libras, ao estar presente nos espaços da educação escolar, não é privilégio, mas constitui-se em conteúdo fundante ao surdo e elemento agregador para o ouvinte em seu processo de formação genérica, de homem cultural.
\end{abstract}

PALAVRAS-CHAVE: Educação Especial. Ensino de Libras. Psicologia Histórico-cultural. Surdez. Educação Infantil.

ABSTRACT: Considering the importance of sign language for inclusion, this article aims to address theoretical issues regarding the teaching of Brazilian Sign Language (Libras) in early childhood education as a mediation resource between deaf and hearing children. Furthermore, the aim is to discuss the impact of sign language instruction on human development from the perspective of Cultural-Historical Psychology (CHP). The article is the outcome of a conceptual bibliographic study (2011-2012). We understand that Libras teaching can promote learning and development of deaf and hearing children, by enabling them to increase their communication partners. Libras provides opportunities for effective linguistic exchanges between deaf and hearing peers; for hearing children, it offers access to a cultural universe to which they are unfamiliar. Studies of primary (Soviet publications) and secondary sources (recent publications on Vygotskian Defectology, language and Libras teaching) indicate the possibility of language development for deaf and hearing children, since teaching Libras as a second language can be seen as a significant resource for hearing children. In conclusion, the study points out the need for further improvement in Libras instruction; to this end, policies that regulate the matter should be enforced. As it is gains recognition within schools, Libras should not be deemed a privilege, but rather it must be understood as fundamental for deaf students, and as an additional element for hearing students during their general upbringing as cultural beings.

KEYWORDS: Special Education. Sign Language Instruction. Cultural-Historical Psychology. Deafness. Early childhood education.

\footnotetext{
${ }^{1}$ Mestre em Psicologia. Docente do Centro Universitário Cesumar. Maringá, Paraná, Brasil - hivicrm@hotmail.com

${ }^{2}$ Doutora em Educaçấo Escolar. Docente da Universidade Estadual de Maringá, Centro de Ciências Humanas Letras e Artes, Departamento de Psicologia, Maringá, Paraná, Brasil - soniashima@uol.com.br

${ }^{3}$ Doutora em Educação. Universidade Estadual de Maringá, Centro de Ciências Humanas Letras e Artes, Departamento de Fundamentos da Educação, Maringá, Paraná, Brasil - tsasilva@uol.com.br
} 


\section{INTRODUÇÃo}

O presente artigo expóe consideraçóes teóricas resultantes de uma pesquisa mais ampla, desenvolvida entre os anos de 2009 e 2013 que buscou pelas contribuiçóes da psicologia vygotskiana para compreensão da aprendizagem e do desenvolvimento de pessoas com deficiência. A essa investigação teórica somou-se uma mais específica (2011-2012), que teve como objeto o estudo da surdez e do ensino de Libras a alunos da educaçáo infantil, sob a perspectiva da Psicologia Histórico-Cultural. Essa perspectiva teoriza que o ser humano náo nasce desenvolvido naquilo que o caracteriza como ser cultural, nem está sujeito somente às leis biológicas impostas geneticamente. Muito mais do que isso, o homem apresenta potencialidades que serão ou não desenvolvidas a partir de relaçôes com seus pares, pela convivência social e apreensóes da cultura própria à sociedade em que este vive e ao que a humanidade já produziu e, ainda, ao que dela teve acesso. Dito de outro modo, para se formarem gêneros humanos particulares emancipados o desenvolvimento ontogenético de pessoas com e sem deficiências depende das oportunidades mediadoras às quais terão acesso.

\section{CONSIDERAÇÓES SOBRE A FORMAÇÃO HUMANA}

A Psicologia Histórico-Cultural (PHC) teve como precursor L. S. Vygotski (18961934), que liderou grupos de estudiosos para o desvendamento da constituição social do psiquismo (LURIA, 2006). A partir de suas teorizaçóes, vários autores se interessaram e estudaram seus preceitos, compondo a escola soviética, que atentou, entre outras coisas, para uma nova teoria explicativa de como o homem se humaniza. Entre estes estudiosos destacamos Alexander Romanovich Luria (1902-1977) e Alexei Nikolaievich Leontiev (1903-1979).

Tal escola psicológica fundamenta-se na compreensão de que o ser humano só pode ser compreendido pela totalidade histórica e pela apreensão dialética da vida humana. Sobre a importância destes dois conceitos Duarte (1996, p. 35) afirma:

$\mathrm{O}$ indivíduo humano se faz humano apropriando-se da humanidade produzida historicamente. O indivíduo se humaniza reproduzindo as características historicamente produzidas do gênero humano. Nesse sentido, reconhecer a historicidade do ser humano significa, em se tratando do trabalho educativo, valorizar a transmissão da experiência histórico-social, valorizar a transmissão do conhecimento socialmente existente.

Reconhecer isso implica aceitar a concepção de que o ser humano não nasce pronto, mas com equipamento biológico inicial sobre o qual se constrói todo um edifício cultural. $\mathrm{O}$ processo educacional (dentro e fora do âmbito escolar) é, pois, um trabalho de reequipamento cultural. Com base nos volumes das "Obras Escogidas" de Vygotski, podemos dizer que a centralidade de sua teoria estava justamente na defesa da tese da formaçáo social do psiquismo, retirando a primazia dos fatores biológicos ou ambientais, para explicar a aprendizagem e o desenvolvimento humanos. Essa defesa em muito nos importa, já que abre espaço para se reconhecer a importância das mediaçôes educacionais não só para apreensão do acervo cultural, mas também para impactar o desenvolvimento humano.

${ }^{4}$ Termo utilizado pela publicaçấo traduzida para o espanhol, da qual fazemos uso. 
Lembramos que as décadas de 1920 e 1930 são marcadas pelas produçóes de Vygotski na direção de comprovação da tese citada. É neste período que este autor, ao pesquisar sobre a aprendizagem e o desenvolvimento à luz do materialismo histórico-dialético, considera que esses dois processos estão em intrínseca relação, de tal modo que a aprendizagem movimenta o desenvolvimento. Também defende que educação escolar deveria estar em defesa do bom ensino, sobretudo para as crianças com deficiências.

Entre os estudos a esse respeito, expostos na coletânea sobre a defectologia (VYGOTSKI, 1997a); destacam-se as discussóes sobre as deficiências sensoriais (cegueira, surdez e surdocegueira). De modo particular, até os dias de hoje as reflexóes do autor sobre a surdez são atuais, embora o contexto soviético, no qual viveu e teorizou, não mais exista. É marcante, por exemplo, sua defesa em prol do uso de uma linguagem viva, de modo que a criança surda possa apreender língua de sinais e desenvolver a oralidade para se realizar como sujeito cultural, considerando que a linguagem verbal se constitui em fator essencial para o alcance da mente humanizada - capaz não somente de reagir sensorialmente a estímulos, mas também de operar com funções psicológicas superiores, apreendendo o mundo e sobre ele interferindo.

Reconhecendo a riqueza de suas teorizaçôes e voltando-nos à educação básica brasileira, como profissionais do campo da psicologia e da educação comum e especial/ inclusiva, preocupa-nos a carência de propostas que ajudem e contribuam para que as crianças surdas, inseridas no contexto escolar regular, aprendam conteúdos que as auxiliem na interação com seus pares ouvintes. É preciso que alunos surdos possam, de fato, beneficiar-se de medidas de acessibilidade, de forma a se apropriarem do conhecimento adequado à sua faixa etária e nível escolar.

Cumpre reconhecer que nas últimas décadas foram muitas as conquistas na área da educação dos surdos no Brasil. O surdo brasileiro dispóe hoje de medidas legais que orientam sua educação e sua inclusão escolar e social. Entre esses dispositivos legais destacamos a Lei n.o 10.436/2002 (BRASIL, 2002), que outorga à Libras o caráter de língua oficial da comunidade surda brasileira, e o Decreto n. ${ }^{5}$ 5.626/2005 (BRASIL, 2005), que propóe medidas de operacionalização da citada lei. Neste sentido o quadro aqui descrito difere em muito do existente à época de Vygotski; contudo, a despeito de uma distância temporal de quase um século entre as suas produções e as dos nossos dias, é possível afirmar que as proposições vygotskianas se revelam muito atuais e seguem contribuindo com os estudos na área da surdez, embora importantes orientaçóes do teórico ainda não sejam consideradas com o devido rigor. Entre as orientaçóes vygotskianas que julgamos pertinentes destaca-se a defesa da adoção da poliglossia (uso de diferentes formas de linguagem) na educação de alunos surdos.

Nessa direção, entre tantas questóes da prática escolar que podem ser suscitadas, destacamos que, ao se estudar o conteúdo curricular próprio da Educação Infantil, não há previsão de ensino, para os alunos ouvintes, da língua brasileira de sinais (Libras), mesmo em situações de matrícula de alunos surdos usuários da Libras nas turmas de educação infantil. Assim, em nossa pesquisa indagamos quanto o ensino da Libras poderia favorecer a aprendizagem e o desenvolvimento de crianças surdas e ouvintes. Justificamos que a inserção desse ensino permitiria à criança surda multiplicar o número de interlocutores, passando a ter acesso a trocas 
linguísticas efetivas com seus pares, enquanto para as crianças ouvintes um novo mundo pode se descortinar, dando-lhes o acesso a um universo cultural até então desconhecido, além de um trabalho corporal diferenciado do existente nesse ensino. Isso significa que com esse ensino as crianças podem se interessar por uma linguagem que emprega recursos como movimento e expressóes corporais e faciais, pois estas crianças se encontram em fase de descoberta do mundo e de como podem nele se situar e sobre ele agir.

\section{Desenvolvimento}

Podemos dizer que a linguagem é mais ampla do que a fala. Ela é fundamental para que o indivíduo se desenvolva enquanto pertencente ao gênero humano, apropriando-se dos usos e costumes, dos conhecimentos e produçóes já elaborados pelos homens e, desta forma, assumindo condutas que são reconhecidas como propriamente humanas.

\section{LINGUAGEM, LIBRAS E DESENVOLVIMENTO HUMANO}

Para a PHC, a linguagem foi sendo criada em estreita relação com a vida prática, guardando caráter simpráxico, já que os homens ao longo da história designaram e nominaram o mundo em decorrência da atividade de trabalho e da cooperação que ela demanda. Ao nos atentarmos aos períodos históricos mais remotos, podemos dizer que inicialmente a linguagem dos homens primitivos dizia respeito a essa prática vivenciada, e só paulatinamente é que ela foi se desprendendo dessa prática, passando a representá-la de modo a assumir caráter semântico (LURIA, 1987).

Segundo Vygotski (2001), embora a aquisição da linguagem verbal possa parecer idêntica nos planos de desenvolvimento filogenético e ontogenético, isso não procede, pois as leis de um não são reeditadas em outro. A criança não precisa realizar a atividade de trabalho, e entrar em cooperação com seus pares para produzir signos e significados. Ela já nasce em um mundo humanizado, que já conta com intervenções e elaboraçóes humanas (seja para apreendêlo, seja para alterá-lo e, também, para representá-lo) e se apropria dele principalmente por meio da linguagem, já existente. Ela não percorre em sua vida o caminho que a humanidade trilhou para formar processos psicológicos superiores.

A criança nasce como um indivíduo da espécie, que traz consigo o desenvolvimento filogenético, e, como se encontra em determinada cultura, a partir de vivências tem contato com seus pares e com mediaçóes competentes, e assim internaliza a cultura em que está inserida e da qual é partícipe. As mediações, juntamente com as internalizaçôes da cultura, são fundamentais para o seu desenvolvimento ontogenético, uma vez que a partir disso é possível a sua transformação de ser em ser humano.

A linguagem, embora não seja a única responsável para formar o que é propriamente humano no ser, não só expressa estados emotivos, como observado nos animais quando faz uso mecânico do som, mas em sua forma verbal engloba o uso de signos (representaçôes imbuídas de significados), a organização do pensamento e diversas outras atividades psicológicas superiores (LURIA, 1987). 
Essas atividades ou funçóes superiores caracterizam o estágio cultural de desenvolvimento, portanto, elas são compreendidas como fundamentais para a humanização do homem, uma vez que permitem que se relacione com seus pares e com o mundo e o ajudam a desvendar e dominar o mundo que o cerca e no qual vive e se reproduz como gênero humano.

É importante registrarmos que, segundo Vygotski (2000), as funções psicológicas superiores (como a memória mediada, a atenção voluntária, o pensamento verbal, a imaginação criadora, entre outras que encontramos somente nos seres humanos) não são inatas ou instintivas, nem resultam do mero amadurecimento das funçóes básicas (com as quais são equipados os homens e os animais). Antes, elas têm origem histórica, formam-se nas relaçóes do indivíduo com o meio cultural e social. Elas desenvolvem-se dialeticamente, a partir de internalizaçóes e apropriaçóes, do aprendizado de valores culturais importantes para a vida em dada sociedade. Na Idade Média, por exemplo, frente a dada organização da sociedade e modo peculiar de se garantir e reproduzir a vida, o próprio psiquismo dos homens era desenvolvido sob determinadas características, e assim sucessivamente nas idades Moderna e Contemporânea. Não podemos pensar que o psiquismo do homem numa sociedade em que a linguagem virtual impera seja o mesmo daquele que vivia numa sociedade sem letramento. Conforme o homem desvenda o mundo e as suas leis, e sobre ele intervém de modo cada vez mais indireto, mais mediado pelo pensamento e por instrumentos, a prática social que protagoniza também se torna mais complexa, o mesmo se dando com o seu psiquismo.

Ante esse embasamento, pensamos que, se a formação do psiquismo tem intrínseca relação não somente com o equipamento biológico já dado desde o nascimento, mas com a prática social, isso nos leva ao compromisso de proporcionar a alunos condiçóes para terem tais funçóes superiores desenvolvidas.

Dando enfoque a uma delas, a linguagem verbal, destacamos que esta pode ser expressa de diversas formas, inclusive pelas vias oral, escrita e gestual. As línguas de sinais ${ }^{5}$, por sua vez, são línguas que fazem uso dos meios visual e espacial para a comunicação e, assim como a língua verbal oral, são meios eficientes de comunicação. Normalmente utilizadas para estabelecer relaçóes com/entre indivíduos surdos; elas transmitem ideias, desejos, vontades e acontecimentos, e, embora tenham estrutura própria, isso não implica em impedimento de apropriação de conteúdos, visto que dizem respeito à sinalização de conteúdos dos mais diferentes níveis de complexidade.

Ante essa constatação, já teorizada por diferentes autores, indagamos: Se ela é assim rica e enriquecedora, por que não oferecê-la às crianças em geral? As crianças não poderiam se valer dos recursos dessa língua, sendo ouvintes ou surdas?

Lembremo-nos de que na Libras a expressão se dá por sinais e que estes envolvem cinco parâmetros importantes para a realização correta do sinal, a saber: configuração de mão, ponto de articulação, orientação, movimento, expressão facial/corporal (FELIPE, 2009).

\footnotetext{
${ }^{5}$ Língua de sinais é um termo utilizado para designar o uso das mãos e expressôes corporal e facial para comunicar-se. Cada país possui a sua língua de sinais. Atribui-se às línguas de sinais o status de língua porque elas também são compostas pelos níveis linguísticos: fonológico, morfológico, sintático e semântico. O que é denominado de "palavra” ou "item lexical” nas línguas oralauditivas é denominado "sinal" nas línguas de sinais. No Brasil, a língua de sinais oficial, é denominada como língua brasileira de sinais (Libras).
} 
Embora os gestos, cotidianamente empregados por usuários de línguas orais, não correspondam a sinônimos dos sinais existentes nas línguas de sinais, eles já estão presentes na vida da criança pequena e servem de base para a aquisição de sinais.

Vygotski (2000, p. 186, tradução nossa) teoriza que o gesto em si não é algo banal, mas é a "escrita no ar". Considera que se usa tal escrita para comunicar algum conteúdo - de ordem emocional, cognitiva, de interação social e outras. Nas palavras de Vygotski, “[...] junto com a linguagem fônica de toda a humanidade foi criado o idioma de gestos para os surdosmudos" (2000, p. 42, tradução nossa). Aqui nessa exposição o autor não diferencia gesto de sinais $^{7}$, mas podemos entender que o gesto é de grande importância para o desenvolvimento da linguagem e entendemos que eles devem ser valorizados na Educação Infantil, assim como os sinais, por se tratar de um período de intensa descoberta de si, de seu corpo e do mundo.

Para compreendermos os escritos de Vygotski sobre a linguagem e a surdez faremos uso da defectologia soviética. A defectologia, segundo Barroco (2007), é um termo utilizado por Vygotski e outros autores soviéticos para fazer referência aos estudos teóricos e de intervenção do que hoje conhecemos como Educação Especial. Esse termo, do qual fazemos uso, é encontrado na obra ${ }^{8}$ traduzida para o espanhol, e não há uma tradução adequada para a língua portuguesa. Vygotski (1997b) faz crítica severa à teorização e à prática da defectologia que se desenvolvia nos anos de 1920 e 1930, postulando novos fundamentos, princípios explicativos e metodologia. O primordial de suas elaboraçóes está na tese central da formação social do psiquismo e na necessidade de se atentar ao que está íntegro para compensar o que está deficitário no desenvolvimento.

A Psicologia Histórico-Cultural liderada por esse autor, que embasa a nova defectologia, compreende a aprendizagem e o desenvolvimento como não iguais (VYGOTSKI, 2001), mas imbricados entre si, assim como o pensamento e a linguagem são distintos, embora inter-relacionados.

Para Vygotski (1996), o processo de encontro do pensamento e da linguagem é fundamental e merece atenção do educador, pois o pensamento precisa chegar paulatinamente à condição de pensamento verbal e a linguagem precisa não simplesmente tornar-se expressiva e receptiva, mas deixar de ser emotiva e de função comunicacional para transformar-se em intelectual. Conforme o autor,

As raízes genéticas e os cursos de desenvolvimento do pensamento e linguagem ficam, até certo ponto, diferentes. A novidade é a intersecção das duas linhas. Isto sucede em uma série de pontos que crescem lenta e paulatinamente, e somente depois se rompe, quer seja o resultado descobrimento ou uma ação estrutural e prolongada de uma troca funcional que coincida com a idade cronológica ou escolar [...] (VYGOTSKI, 2001, p. 116, tradução nossa).

\footnotetext{
${ }^{6}$ Termo utilizado na época de Vygotski.

${ }^{7}$ A especificação dos termos decorreu de estudos da área da linguística. Não era preocupação de Vigotsky diferenciar gestos que acompanham a oralidade, dos sinais convencionais empregados nas línguas espaço-visuais, mas era sua intenção dar ênfase à importância das línguas sinalizadas para o desenvolvimento intelectual de indivíduos surdos.

${ }^{8}$ Vygotski, L. S. Obras Escogidas. Tomo V. Trad. Lydia Kuper. Madrid: Visor, 1997b.
} 
Saber da gênese dessas funçôes propriamente humanas permite que se atue para sua emergência e desenvolvimento - que se constitui em compromisso ético com as finalidades da educação escolar. Para Vygotski (2001, p. 104, tradução nossa),

Este momento crucial, a partir do qual a linguagem se faz intelectual e o pensamento se faz verbal, se reconhece pelas características inconfundíveis e objetivos, segundo os quais podemos julgar com certeza se foi ou não produzida esta mudança no desenvolvimento da linguagem e, nos casos de uma evolução anormal ou retardada, em quanto tempo se deslocou este momento em comparação com o desenvolvimento anormal da criança.

A partir desse momento, a criança apresenta linguagem abstrata, ou seja, sem o uso das palavras, mas sim das "ideias de palavras", como escreve Vygotski (2001), ou seja, o pensamento. De acordo com Petrovski (1980, p. 292, tradução nossa) “[...] pensamento é o processo psíquico socialmente condicionado de buscas e descobertas do essencialmente novo e está indissoluvelmente ligado à linguagem”. Então, é fundamental que a criança deixe a relação com o mundo que se baseia nos processos sensoriais e inicie processos de conhecimento do mesmo, indo para além do que informa a experiência empírica, em geral sincrética, e que se pauta em impressóes e percepçóes. Aliás, para Vygotski (1997a) e para Luria (1987), fazer ciência é justamente ultrapassar a aparência e identificar as múltiplas determinaçóes do real que não se apresentam de imediato, mas que só são acessíveis pelo pensamento verbal, pelas relações estabelecidas entre os fenômenos, pela busca das causalidades e da gênese histórica dos fatos. (Daí se entender que se trata de uma teoria genética.)

Nas palavras de Petrovski (1980):

Somente a linguagem torna possível a abstração de propriedades do objeto de conhecimento e o que se pode fixar da representação, o mesmo conceito em uma palavra especial. A ideia adquire na palavra a envoltura material necessária, na que ela se converte em realidade direta para as demais pessoas e para nós mesmos. O pensamento humano - seja qual for a forma como se realiza - é impossível sem o idioma. Cada pensamento surge e se desenvolve em conexáo inseparável com a linguagem (PETROVSKI, 1980, p. 295, tradução nossa).

A linguagem verbal, com sua natureza histórico-social, permite ao homem organizar seu pensamento, planejar açóes e apresentar intencionalidades que poderão tornar-se externalizadas. $\mathrm{O}$ pensamento torna-o capaz de fazer uso intencional de instrumentos, atuando sobre a natureza e seu comportamento.

É possível imaginarmos quanto prejuízo a falta da linguagem (verbal oralizada, sinalizada) acarreta ao desenvolvimento social, intelectual e emocional do indivíduo, como apontam Capovilla e Raphael (2001) e Sacks (2010).

No campo do desenvolvimento intelectual a linguagem constitui-se em instrumento psicológico. Vygotski (1997a) escreve que

1. No comportamento do homem surge uma série de dispositivos artificiais dirigidos ao domínio dos próprios processos psíquicos. Por analogia com a técnica, estes dispositivos podem receber com toda justiça a denominaçáo convencional de ferramentas ou instrumentos psicológicos (técnica interna segundo a terminologia de E. Claparéde, modus operandi, según R. Thurnwald).

$[\ldots]$ 
3. Os instrumentos psicológicos são criaçôes artificiais; estruturalmente são dispositivos sociais e não orgânicos ou individuais; estão dirigidos ao domínio dos processos próprios ou alheios, o mesmo que a técnica o está ao domínio dos processos da natureza.

4. Como exemplo de instrumentos psicológicos e de seus complexos sistemas podem servir a linguagem, as diferentes formas de numeração e cômputo, os dispositivos mnemotécnicos, o simbolismo algébrico, as obras de arte, a escrita, os diagramas, os mapas, os desenhos, todo gênero de signos convencionais, etc.

5. Ao estar inserido no processo de comportamento, o instrumento psicológico modifica globalmente a evolução e a estrutura das funçôes psíquicas, e suas propriedades determinam a configuraçáo do novo ato instrumental do mesmo modo que o instrumento técnico modifica o processo de adaptação natural e determina a forma das operaçôes laborais (p. 65, tradução nossa).

Esses instrumentos provocam o reequipamento cultural; levam à superação das funçóes psicológicas elementares, também presentes em animais, pelas funçóes psicológicas superiores de origem cultural e de domínio voluntário dos sujeitos. Essa intencionalidade marca a presença da consciência, da voluntariedade, do que é próprio aos seres humanos, devendo ocorrer em pessoas com e sem deficiências.

A Libras pode ser entendida como um instrumento psicológico. Por meio da sua aquisição o sujeito surdo tem alterado o seu psiquismo. Por meio dela pode se dar a sistematização do ensino e se descortina a possibilidade da aprendizagem de conteúdos tanto do cotidiano como científicos, sobretudo na escola. Sobre isso, lembramos que Vygotski (2001) considera que o desenvolvimento não resulta apenas da maturação biológica ou de um processo linear, mas atravessa diversas crises dinâmicas e dialéticas, sendo revolucionárias para a formação humana. Tais crises são necessárias e derivam tanto do próprio desenvolvimento biológico como das tentativas que o sujeito faz para superar dificuldades encontradas. Estas superaçóes, possibilitadas por mediações instrumentais, culminam em novas aprendizagens.

As mediações instrumentais do professor, do intérprete e demais profissionais direcionam a criança surda ou ouvinte, com ou sem deficiência, à superaçóes, provocando a movimentação da sua zona de desenvolvimento próximo. Lembramos que o nível real de desenvolvimento se refere às aquisiçóes já conquistadas pelo sujeito, que lhe permite, por exemplo, solucionar sozinho o que anteriormente não conseguia. A zona de desenvolvimento proximal, por sua vez, diz respeito às apropriaçóes ainda em curso de conhecimentos de diferentes níveis de complexidade, que demandam o auxílio de outro indivíduo mais experiente ou de recursos mediadores condizentes (como livros, manuais, etc.). Por esse entendimento, consideramos que um bom ensino não pode manter-se no nível de desenvolvimento real, mas precisa ter como foco a intervenção junto à zona de desenvolvimento proximal, construindo bases para novas aprendizagens, de modo contínuo e ilimitado.

Vygotski (1997) relata os caminhos percorridos até se perceber que, no essencial, a aprendizagem ocorre da mesma maneira entre alunos surdos e ouvintes. No Tomo V das Obras Escogidas, no início de seus escritos, o autor defende que o ensino da linguagem aos surdos é um problema central para a educação destes, pois o desenvolvimento num plano mais elevado só ocorreria em detrimento da apropriação da linguagem verbal em sua forma oral.

Movido por esse entendimento e buscando dimensionar o quanto a linguagem é determinante para o desenvolvimento humano no ser, o teórico faz uma comparação: 
A surdo-mudez ${ }^{9}$ no ser humano é uma desgraça muitíssima maior que a cegueira, pois o bloqueia da comunicação com as pessoas. A mudez, ao privar o homem da fala, separa-o da experiência social e o excluí do vínculo comum. A surdo-mudez é uma insuficiência predominantemente social. Destrói mais diretamente que a cegueira os nexos sociais da personalidade. Assim, o primeiro problema da pedagogia de surdos consiste em restituir a fala ao surdo-mudo. Isto é possível. A surdez implica, no geral, só uma enfermidade dos nervos e centros auditivos, e não dos fonadores (VYGOTSKI, 1997, p. 87, tradução nossa).

Ainda teorizando sobre a importância do desenvolvimento da fala oral para o surdo, afirma:

[...] de todos os modos, ensinar a fala a um surdo-mudo implica não só dar-lhe a possibilidade de comunicar-se com as pessoas, mas também de desenvolver a consciência e pensamento, a autoconsciência. É restituir-lhe a condição humana. Assim, do ponto de vista científico e cultura, a mímica está condenada (VYGOTSKI, 1997, p. 88, tradução nossa).

Nos excertos citados percebemos que Vygotski considerou em seus estudos iniciais, que que a fala é instrumento para o pleno desenvolvimento. Com intençóes positivas para o surdo alcançar o desenvolvimento, o autor aponta a importância de restituir-lhe a fala. Em período inicial, Vygotski entendia que a "mímica" - língua de sinais, no nosso entendimento não auxiliava na formação das funçóes psicológicas superiores, além de impedir a aquisição da fala. A este respeito o autor teoriza:

A questáo do ensino da linguagem aos surdos-mudos constitui o problema básico e central de sua educação social. Sem dar-lhe alguma solução não podemos empreender na prática e na reorganização de toda a escola sobre a base de novos princípios. O novo regime da escola e o novo sistema de ensino da linguagem só podem ir organizando-se de forma paralela, desenrolando-se organicamente a partir das mesmas ideias (VYGOTSKI, 1997, p. 341, tradução nossa).

Não obstante, aproximadamente uma década depois, constatando a insuficiência da língua oral para promover o desenvolvimento intelectual do surdo, o autor aponta que a "mímica" e a linguagem escrita podem ser um caminho alternativo para o desenvolvimento. Nesse sentido, afirma que "[...] a linguagem não está ligada necessariamente ao aparelho fonador, pode se realizar em outro sistema de signos, assim como a escrita pode ser transformada da forma visual na tátil.” (VYGOTSKI, 1997, p. 186, tradução nossa).

O que Vygotski teorizou em meados de 1930 tornou-se um paradigma aceito nos dias atuais. Em conformidade com os pressupostos vygotskianos de um ensino para surdos fundado na poliglossia encontramos atualmente uma forte defesa de uma educação bilíngue para aprendizes surdos. O bilinguismo refere-se ao domínio e uso de duas línguas. No Brasil, o bilinguismo para os surdos estabelece o uso da Libras, como primeira língua e da língua portuguesa na modalidade escrita, como segunda língua.

O autor, então, critica a pedagogia que se firma somente sobre a deficiência, e não sobre o que se encontra íntegro, de modo a levar à compensação. Também defende a "poliglossia", que faz referência à utilização de duas ou mais línguas, como a sinalizada, a oralizada e a escrita,

${ }_{9}^{9}$ Termo utilizado na época de Vygotski. 
por exemplo. Vygotski (1997) também critica a pedagogia que focaliza a falta, a deficiência, sem considerar as potencialidades que o indivíduo possui ou que é potencialmente capaz de obter mediante recursos, métodos e mediaçóes adequadas (GÓES, 2002).

Entendendo a língua de sinais como instrumento psicológico fundamental para o surdo, Vygotski afirma:

[...] a luta da linguagem oral contra a mímica, por regra geral, sempre termina com a vitória da mímica, não porque esta seja, do ponto de vista psicológico, a verdadeira linguagem do surdomudo; não porque seja mais fácil - como dizem muitos pedagogos -, mas porque constitui uma autêntica linguagem em toda a riqueza de seu significado funcional (1997, p. 231, tradução nossa).

Pelo exposto podemos dizer que Vygotski reconhece que a linguagem não depende somente de som, mas compreende algo mais amplo e complexo, pois pela linguagem nos diferimos dos demais seres vivos, uma vez que a linguagem dos animais apresenta características reprodutoras, sem o uso do pensamento, do planejamento.

Desta forma, é fundamental que o homem se aproprie da linguagem e dos conhecimentos formais aprendidos nos âmbitos escolares. É através das relaçóes com outros seres humanos, de aprendizados com outro ser humanizado, que o homem aprende a viver no mundo e a atuar sobre ele. Pensando na escolarização do surdo e em sua humanização, Vygotski escreve (1997, pp. 342-343):

[...] a escola determina o sistema, e não ao contrário. [...] O problema da linguagem dos surdosmudos não será solucionado por um método especial, e sim, pela reestruturação geral da escola com base nos princípios da educação social. [...] O ponto de vista exposto, absolutamente, não nega a importância do significado especial do ensino da linguagem. [...] a luta pela frase inteira, pela palavra - contra a preparação fonética da linguagem; a luta da unidade da linguagem oral - contra a brincadeira da mímica; a luta pela estimulação natural do desenvolvimento da linguagem tomado da vida - contra sua assimilação ineficaz nas liçóes [...] (tradução nossa).

Nos seus estudos no campo da defectologia, Vygotski afirma que os processos humanos têm início nas relaçóes sociais, portanto o processo de desenvolvimento do psiquismo do ser humano ocorre na direção de fora para dentro, do plano interpsíquico para o intrapsíquico; ou seja, o que é criado e objetivado entre os homens e entre eles circula passa a ser conteúdo a ser internalizado e apropriado por cada um, tornando seu o que é uma produção social. Assim, o pleno desenvolvimento do surdo requer que ele faça seu o que outros surdos e ouvintes produziram. O seu psiquismo deve ser povoado por essas elaboraçóes. Por esse modo "a criança, cujo desenvolvimento encontrou dificuldade devido à sua deficiência, não é simplesmente uma criança menos desenvolvida que as outras, mas sim que se desenvolveu de outra maneira" (VYGOTSKI, 1997, p. 12).

Vygotski (1997) teoriza que o defeito e a limitação são conceitos de menor importância no desenvolvimento humano, pois, devido ao aparecimento de dificuldades próprias da condição das pessoas com deficiência ocorre a estimulação de um avanço elevado e intensificado, criando condiçóes de superaçóes que elas podem alcançar, apesar das dificuldades. Escreve que quando enfrentam dificuldades, obrigam-se a buscar vias indiretas para superá-las. 
A interação com o meio as impulsiona a realizarem compensaçôes. Isto é notório pelo fato de que os rumos dos processos compensatórios e os dos processos de desenvolvimento, via de regra, não estão delimitados somente pelo tipo/característica das deficiências, mas sobretudo pela conjuntura na qual estão inserida essas pessoas. Dito de outro modo, o autor expóe que a posição social, e não necessariamente os limites biológicos, é que assume ou exerce papel fundante na direção e amplitude da humanização dessas pessoas.

Lembramos que toda superação e compensação são histórico-culturais, ou seja, são desenvolvidas a partir das condiçóes ofertadas pelo meio social em que o indivíduo se encontra, ainda que se valha, por exemplo, de próteses ou órteses. Desta forma, segundo Vygotski (1997), os mecanismos de compensação e superação são dependentes das condiçóes ofertadas, portanto, podem ser adequados ou empobrecidos.

Como compensação, entendemos todo o processo de estratégias culturais que visam a superação dos limites biológicos. Neste sentido, o sujeito surdo, não possuindo a audição como via de acesso entre ele e o mundo, pode ser estimulado de forma a desenvolver outra maneira de estabelecer relaçóes que não seja a auditiva, em especial para o uso da linguagem. Então, a partir das compensaçóes o surdo é capaz de superar o que o impede de se estabelecer e conviver no mundo fazendo uso do que se encontra intacto, por exemplo, a visão.

Desta forma, a maneira como os indivíduos surdos são percebidos e tratados é que favorece ou não o seu processo de desenvolvimento, e a educação precisa estar centrada no potencial que o ser humano possui para desenvolver-se, e não na deficiência apresentada. Assim, a insuficiência estaria na sociedade, e não na pessoa com deficiência. "(...) A cegueira e a surdez como defeitos físicos permanecerão ainda por muito tempo na Terra. O cego seguirá sendo cego e o surdo, surdo; mas eles deixaráo de ser pessoas com defeito, porque a deficiência é um conceito social" (VYGOTSKI, 1997, p. 82).

Temos, por essa teorização, que a concepção de que a deficiência impossibilitaria a educação e o desenvolvimento é substituída pelo princípio de que o defeito implica em uma dupla influência no desenvolvimento da criança. Assim,

Por um lado, a deficiência atua diretamente como tal, criando prejuízos, obstáculos e dificuldades na adaptação da criança. Por outro lado, exatamente a causa do defeito cria obstáculos e dificuldades no desenvolvimento e altera o equilíbrio normal, serve de estímulo ao desenvolvimento de caminhos colaterais na adaptação (...) o desenvolvimento cultural é a esfera fundamental pela qual se torna possível a compensação da deficiência. De onde resulta impossível um desenvolvimento orgânico posterior, se abre ilimitadamente o caminho para o desenvolvimento cultural. (VYGOTSKI, 1997, p. 186, tradução nossa).

A teoria vygotskiana aposta que o homem pode superar os limites da natureza: uma criança exposta a condiçóes adequadas superará, paulatinamente, a condição biológica, e se guiará, cada vez mais, pelo pensamento, pela consciência. Para tanto, é necessário aprender, com seus pares e com o já elaborado pela humanidade, maneiras de estar e de se apropriar do mundo. Isso requer que ela tenha domínio de uma língua viva e eficiente, tanto para a comunicação quanto para a organização do seu psiquismo. Assim a criança apresenta trocas com o mundo no qual vive, apropria-se dele e sobre suas apropriaçóes cria novas elaborações ou objetivações (Barroco, 2007). 
Em uma proposta bilíngue de educação de surdos, a apropriação pela criança de uma língua viva, que possa ser acessada sem barreiras sensoriais - portanto, uma língua gestual - pressupóe a atuação de professores e intérpretes de língua de sinais. Para Lacerda (2009), no ensino infantil o intérprete também assume a postura de educador, ensinando sinais e ampliando a compreensão da língua gestual para a criança surda. Assim, temos que essa língua assume caráter instrumental e compensatório.

A escola que se propóe bilíngue e que oportuniza a experiência de inclusão de alunos surdos deve apresentar seus conteúdos, simultaneamente, em língua portuguesa (oral e escrita) e em Libras. Essa oferta simultânea, de conteúdos em duas línguas de modalidades distintas (uma de natureza oral-auditiva e outra de natureza visual-gestual) exige formação especializada tanto do professor, quanto do intérprete de língua de sinais. Além disso, a aprendizagem do aluno surdo, em processo de inclusão, também requer o estabelecimento de uma estreita sintonia entre professor e intérprete - ambos devendo assumir função de mediadores que promovem a compensação dos limites físicos, em prol da formação do talento cultural. Esse talento pode ser compreendido, com base em Vygotsky e Luria (1996), como a capacidade de empregar funções psicológicas íntegras, que não estão afetadas pela deficiência, de modo consciente e funcional.

Contudo, nem sempre isso que defendemos é aplicado na cotidianidade da escola. O professor, assim como o intérprete, por conta da própria formação teórica e metodológica, ou pelas condiçóes objetivas da escola, da docência e da interpretação, podem não intervir adequadamente junto ao aluno surdo. $\mathrm{O}$ intérprete, especificamente, pode realizar poucos sinais em Libras durante as aulas, empobrecendo a interpretação e impactando no ensino dos conteúdos.

\section{CONCLusóes}

O que expusemos no plano teórico nos inspira a pensar a nossa prática como intérprete de Libras e como docentes que atuam no ensino superior com formação inicial e continuada de professores e de psicólogos. Além do que a literatura expóe, o nosso convívio com a educação escolar nos oferece subsídios a respeito da distância entre o que é legislado e o que é implementado no campo educacional. Temos notado o despreparo da comunidade escolar para acolher pedagogicamente o aluno surdo. Lembramos que a partir do DecretoLei 5.626/2005 (BRASIL, 2005) ficou estabelecido que a Libras constitui-se como disciplina curricular obrigatória nos cursos de formação de professores, nos cursos de Fonoaudiologia e nas licenciaturas em geral.

Apesar do disposto legalmente, ainda é necessário que estejamos vigilantes quanto à qualidade dos cursos de formação inicial (graduação) e continuada, para que realmente instrumentalizem os profissionais para a formação humana. Entendemos ser fundamental o papel da linguagem viva ${ }^{10}$ para a constituição do psiquismo do ser humano cultural (Vygotski, 1997), como apontamos anteriormente. Assim, consideramos ser necessária a atuação de

\footnotetext{
${ }^{10}$ A linguagem em si pode ser entendida como um código, ou seja, apresentar-se estática, sem flexibilidades. A linguagem adjetivada como viva, na perspectiva em que estamos empregando, refere-se a uma linguagem não só entendida como composta por palavras, mas de uso nas situaçóes cotidianas que permitem a formação da genericidade nos indivíduos, a formação cultural, e ainda, a singularidade. Ela é viva porque lhes permite estabelecer relaçôes entre si e com o mundo, apreendendo-o. Para Vygotski (1997), ela está relacionada com o trabalho.
} 
intérpretes que possam ir além da tradução mecanizada. É importante que haja intencionalidade no ensino da linguagem desse modo adjetivada.

O emprego da Libras como primeira ou segunda língua ${ }^{11}$ requer dos profissionais e da instituição escolar intencionalidade, sistematização e planejamento do ensino. Nesse sentido, ao ser ensinada na escola, a Libras apresenta o status de segunda língua para os ouvintes e primeira língua para os surdos, e torna-se não apenas meio de comunicação, mas saber científico. Sobre isto Vygotski (2001, p. 198) faz a seguinte teorização:

[...] as condições internas e externas do estudo de um idioma estrangeiro [segunda língua] e a formação dos conceitos científicos coincidem em seus traços essenciais e, o que é mais importante, se diferenciam por igual das condiçōes de desenvolvimento da língua materna e dos conceitos espontâneos, já que umas e outras se tornam também semelhantes. A diferença aqui e ali se radica em primeiro lugar na intervenção da instrução como novo fator de desenvolvimento (grifos do autor, tradução nossa).

Deste modo, o processo de ensino e aprendizagem envolvido no ensino da Libras como primeira e segunda língua se aplica às outras ciências e saberes alvos da educação escolar.

Em uma intervenção prática de ensino de Libras que realizamos em 2012, para crianças ouvintes e uma criança surda, em um Centro de Educação Infantil, notamos fatos relevantes. Um deles refere-se à interação da aluna surda com os demais colegas de classe. Após algumas aulas de Libras observamos que houve um aumento significativo na frequência do seu uso na comunicação entre as crianças. Nessa experiência, o ensino dessa língua se deu empregando o próprio conteúdo programático da educação infantil previsto para a turma.

Outro fato diz respeito ao emprego de alguns sinais em Libras, por crianças ouvintes ao se comunicarem com outras também ouvintes. Juntamente com a comunicação oral elas se comunicavam também pela Libras. Os sinais empregados por elas podem ser entendidos como "balbucios em sinais", o que nos indicou certo interesse e envolvimento com a Libras e revelou indicativo de desenvolvimento: houve aprendizagem do ensinado, bem como uso adequado seja na forma, seja no contexto em que foi empregada.

Indagamos se para as crianças ouvintes a apropriação e emprego de sinais em Libras poderia ser compreendido como um "jogo", um brinquedo, um desafio. Certamente que sim. Lembramos que para Leontiev (2006) a atividade principal da criança pré escolar, aquela que movimenta o desenvolvimento como um todo, é o brinquedo. Para Vygotski (1996), o brinquedo é coisa séria, visto que forma e opera com a imaginação e o simbolismo, ao mesmo tempo em que incide na zona de desenvolvimento proximal. Por meio do brinquedo, a criança realiza atividades que lhes são impossíveis no plano real. Brincar de ser surdo ou comunicarse de modo mais lúdico, com regras e imaginação explícitas, foram aspectos que notamos naquelas crianças.

Consideramos que o ensino de Libras promove o desenvolvimento psicomotor, com atividades significativas e contextualizadas, além de socialmente útil. Avaliamos que o uso dessa língua é capaz de promover o desenvolvimento das funções psicológicas superiores em sujeitos

\footnotetext{
${ }^{11}$ Para crianças ouvintes brasileiras a Libras é uma segunda língua, assim como o inglês, o espanhol, o alemão e outras, pois a primeira língua é a Língua Portuguesa, a língua materna (ou primeira língua).
} 
surdos e ouvintes. Como primeira língua para sujeitos surdos, a Libras é a porta de entrada para as informaçóes do ambiente em que vivem e para apropriaçáo de conceitos que estimulam e movimentam o desenvolvimento das funçóes propriamente humanas.

A Libras é fundamental para que o sujeito surdo alcance o patamar mais alto no desenvolvimento, tornando-se humanizado no nível cultural próprio aos dias contemporâneos. Por isso, salientamos a necessidade de uma formação técnica com aprofundamento e com compromisso com esse processo de formativo, para que não ocorram o abandono presencial e nem o abandono intelectual.

Com o exposto destacamos a necessidade de que os profissionais da educação conheçam a Libras e as especificidades que envolvem a educação do aluno surdo. Reafirmamos, ainda, a expectativa ética de que os centros de Educação Infantil assumam o compromisso de oportunizarem ao aluno surdo as condiçóes para que se dê o processo de hominização, como resultado da apropriação de conteúdos escolares em língua de sinais, e que para o aluno ouvinte se descortinem novas oportunidades de aprendizagem por meio do acesso ao maior patrimônio da comunidade surda brasileira: a língua brasileira de sinais. Entendemos que o ensino da Libras na educação infantil é uma medida que pode verdadeiramente favorecer a consolidação de uma escola inclusiva.

\section{REFERÊNCIAS}

BARROCO, S. M. S. A educação especial do novo homem soviético e a psicologia de L. S. Vigotski: implicaçóes e contribuiçóes para a psicologia e a educação atuais. 2007. Tese (doutorado em Educação) - Universidade Estadual Paulista, Araraquara, 2007.

LACERDA, C. B. F. de. Intérprete de Libras: em atuação na educação infantil e no ensino fundamental. Porto Alegre: Mediação. 2009.

BRASIL. Decreto no 5.626, de 22 de dezembro de 2005. Regulamenta a Lei no 10.436, de 24 de abril de 2002, que dispóe sobre a Lingua Brasileira de Sinais - Libras, e o art. 18 da Lei no 10.098, de 19 de dezembro de 2000. 2005. Disponível em: <http://www.planalto.gov.br/ccivil_03/_ato2004-2006/2005/ decreto/d5626.htm>. Acesso em: 20 mar. 2012.

BRASIL. Lei no 10.436, de 24 de abril de 2002. Dispóe sobre a Língua Brasileira de Sinais - Libras e dá outras providências. 2002. Disponível em: <http://www.planalto.gov.br/ccivil_03/leis/2002/ L10436.htm>. Acesso em: 20 out. 2012.

CAPOVILLA, F. C.; RAPHAEL, W. D. Dicionário enciclopédico ilustrado trilíngue da língua de sinais brasileira. Vol. I: Sinais de A a L. São Paulo: Editora da Universidade de São Paulo. 2001. p.17-25.

DUARTE, N. A escola de Vigotski e a educação escolar: algumas hipóteses para uma leitura pedagógica da psicologia histórico-cultural. Psicologia USP, v.7, n.1/2, p.17-50, 1996.

FELIPE, T. A. Libras em contexto: curso básico. 9 ed., Rio de Janeiro: WalPrint Gráfica e Editora. 2009. FENEIS. Federação Nacional de Educação e Integração dos Surdos. Intérpretes. (s/d). Disponível em: <http://www.feneis.org.br/page/interpretes.asp>. Acesso em: 12 jan. 2013.

GÓES, M. C. R. Psicologia, Educação e as temáticas da vida contemporânea. In: M. K. Oliveira; T. C. Rego; D. T. R. Souza (Org.). Relaçôes entre desenvolvimento humano, deficiência e educação: contribuiçóes da abordagem histórico-cultural. São Paulo: Ed. Moderna. 2002. 
LURIA, A. R. Vigotskii. In: L. S. VIGOTSKII; LURIA, A. R.; A. N. LEONTIEV (Org.). Linguagem, desenvolvimento e aprendizagem. Tradução de Maria da Penha Villalobos. 10. ed. São Paulo: Ícone, 2006. p.6-17.

. Pensamento e linguagem: as últimas conferências de Luria. Porto Alegre: Artes Médicas. 1987.

PETROVSKI, A. Psicologia general: manual didáctico para los institutos de pedagogia. Moscú:

Editorial Progresso, 1980.

SACKS, O. Vendo Vozes: uma viagem ao mundo dos surdos. Traduçáo de Laura Teixeira Motta. São Paulo: Companhia de Bolso, 2010.

VYGOTSKI, L. S. Obras escogidas. Tomo IV. Madrid: Visor. 1996.

. Obras escogidas. Tomo I. Trad. José Maria Bravo. Madrid: Visor. 1997a.

. Obras escogidas. Tomo V. Trad. Lydia Kuper. Madrid: Visor. 1997b.

. Obras escogidas. Tomo III. Madrid: Visor. 2000.

. Obras escogidas. Tomo II. Trad. José Maria Bravo. Madrid: Visor. 2001.

Recebido em: 08/04/2013

Reformulado em: 11/10/2013

Aprovado em: 21/11/2013 